\title{
O USO DE GEOTECNOLOGIAS NO ATENDIMENTO AOS SERVICOS PÚBLICOS EM SANTO ÂNGELO/RS: UMA ANÁLISE SOBRE O CIDADÂO MOBILE ${ }^{1}$
}

\author{
Vitor Colleto dos Santos ${ }^{2}$; Natália Lampert Batista ${ }^{3}$
}

\section{RESUMO}

Cada vez mais tem se observado o uso das geotecnologias para a análise do espaço e gestão do território. Dentre as razões que levam a utilização dessas ferramentas, destaca-se o seu potencial de permitir, através de informações e dados (geo)espaciais, a solução a demandas solicitadas pelos habitantes de um determinado município e auxílio à atuação dos encarregados a atenderem tais demandas, por exemplo. Com base nessa, cada vez mais, significativa democratização de (geo)tecnologias, o município de Santo Ângelo (RS) implantou o aplicativo Cidadão Mobile, que permite pensar e compreender. O presente trabalho, portanto, buscou fazer uma breve explicação de quais devem ser os procedimentos adotados pela população para manusear o aplicativo Cidadão Mobile que é oferecido para contribuírem com a gestão e organização do espaço de Santo Ângelo. Conclui-se que as (geo)tecnologias estão cada vez mais nesse meio para isso: dar fomento a adoção de políticas públicas sérias e compromissadas a atender da melhor forma as urgências dos habitantes. Em Santo Ângelo, com o Cidadão Mobile, a gestão territorial e a população só tendem a ganhar com isso. Do mesmo modo, a promoção de uma cultura cidadã tem impacto na construção de pessoas mais críticas e capazes de intervir conscientemente em suas realidades.

Palavras-chave: Cidadão Mobile; Desenvolvimento Municipal; Gestão Territorial; Informação Geográfica; Políticas Públicas.

Eixo Temático: Tecnologia, Inovação e Desenvolvimento Sustentável - TIDS.

\section{INTRODUÇÃO}

A análise e o entendimento da espacialização das áreas que demandam a realização de serviços públicos são cruciais para a tomada de decisão frente à gestão das políticas de atendimento às necessidades dos habitantes do município.

\footnotetext{
${ }^{1}$ Trabalho desenvolvido para a disciplina de "Geotecnologias na Contemporaneidade" (GCC1110), do Curso de Geografia Licenciatura da Universidade Federal de Santa Maria (UFSM).

${ }^{2}$ Autor/Apresentador - Discente do curso de Geografia Licenciatura da UFSM e bolsista do Programa de Licenciatura (PROLICEN/UFSM), vitorcolleto@gmail.com.

${ }^{2}$ Orientadora - Docente do Departamento de Geociências da UFSM, natalia.batista@ufsm.br.
} 
Com base nesta afirmação, é que se estabelece a importância da Geografia para com a compreensão das questões espaciais e de sua respectiva organização.

Com o intuito de auxiliar a ciência geográfica no atendimento às demandas de gestão e organização do espaço, nesta seara, emergem as (Geo)tecnologias como uma alternativa que se apresenta sobremaneira ao despontar da "era digital" e, como apresentam Polidoro e Barros (2010, p. 85):

[...] vêm se destacando em diversas áreas do conhecimento como uma ferramenta de trabalho extremamente útil devido à sua versatilidade e capacidade no tratamento de grande volume de dados espaciais, auxilia o planejamento e tomada de decisões que necessitem realizar análise espacial. (POLIDORO; BARROS, 2010, p. 85).

Nesta mesma perspectiva, segundo Laudares (2014, p. 21), "[...] a democratização da informação geográfica mostra-se cada vez mais importante na vida das pessoas. [...] vem revolucionando a forma de conceber, criar, estruturar armazenar, manipular, analisar e distribuir mapas". Assim, a correta descrição de fatos relacionados ao cotidiano do município, que é fornecida pelas mais diversas ferramentas geotecnológicas (Sistemas de Informação Geográfica - o SIG, ferramentas de geoprocessamento e Sistema Global de Navegação por Satélite GNSS), que disponibilizam à população a possibilidade de interagir com as informações geográficas.

As geotecnologias podem ser entendidas como as novas tecnologias ligadas às Geociências, as quais trazem avanços significativos no desenvolvimento de pesquisa, em ações de planejamento, em processos de gestão, manejo e outros tantos aspectos relacionados a estrutura do espaço geográfico. Essas considerações tornam-se importantes à medida em que profissionais de diversas áreas atuam diretamente com questões espaciais (LAUDARES, 2014, p. 22).

No caso de Santo Ângelo, localizado no Noroeste do Rio Grande do Sul (Figura 01), pelo aplicativo Cidadão Mobile as pessoas não são somente receptoras da informação, mas também passam a atuar como geradoras dela, contribuindo para as melhorias nos serviços públicos que lhes são oferecidos. 
Figura 01: Localização de Santo Ângelo/RS, por uma ferramenta geotecnológica.

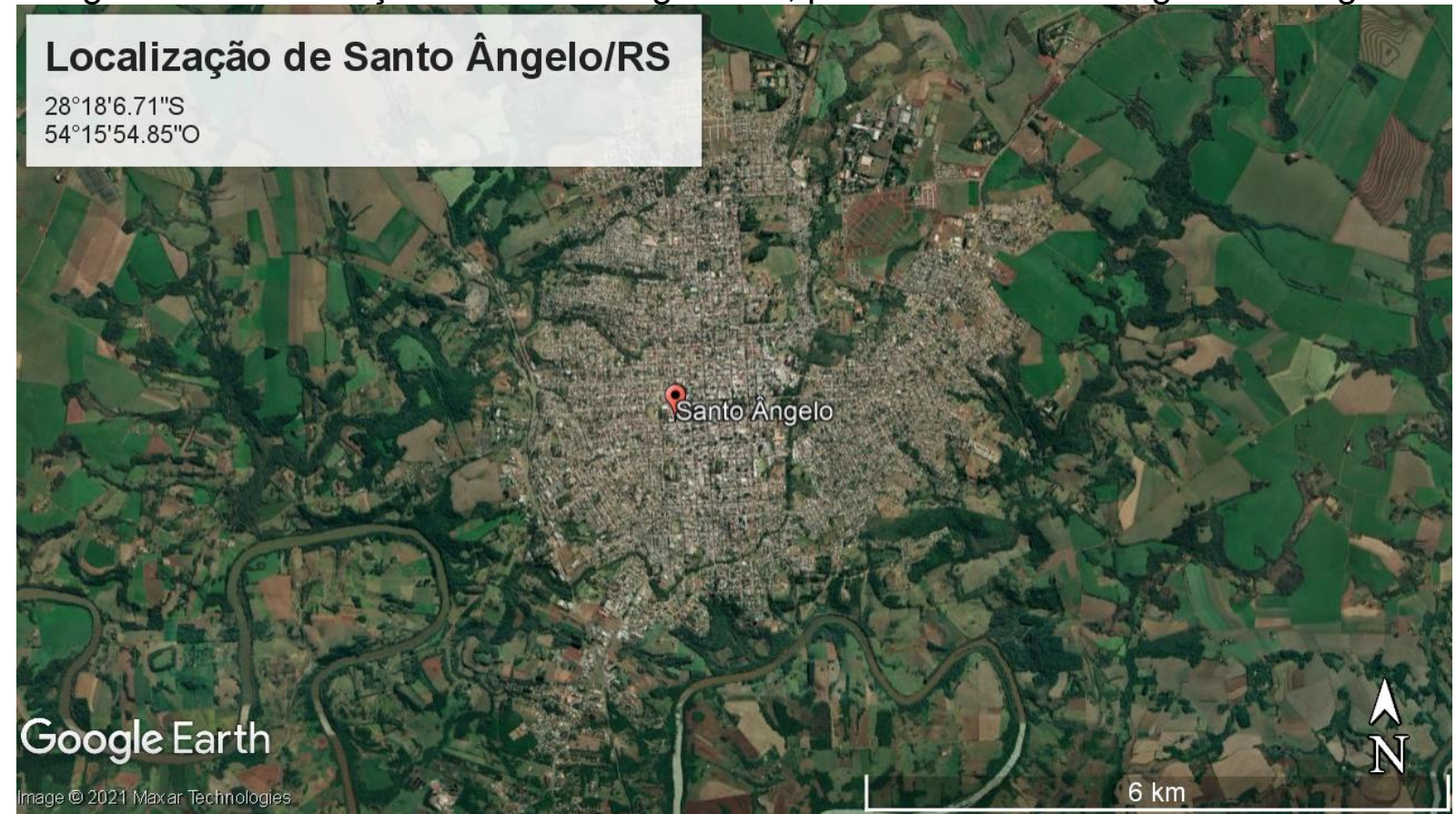

Fonte: Google Earth (2021, adaptado).

Conforme considera Mendes (2019, p. 35), “[...] essas ferramentas são importantes, pois podem contribuir e fornecer distintas informações para diferentes trabalhos" (MENDES, 2019, p. 35), mas não só isso. O Cidadão Mobile é um software que permite também um maior contato dos moradores do município com o poder público local e, mediante tal aproximação, pode-se chegar a resolução conjunta de problemas que afligem a comunidade, desde a manutenção de logradouros públicos até a fiscalização tributária, por exemplo.

O presente trabalho, portanto, buscou fazer uma breve explicação de quais devem ser os procedimentos adotados pela população para manusear o aplicativo Cidadão Mobile que é oferecido para contribuírem com a gestão e organização do espaço de Santo Ângelo. O produto geolocalizado e, por conseguinte, geotecnológico, gerado pelas diversas funcionalidades do aplicativo será de pronto utilizado pela Prefeitura Municipal que fará os encaminhamentos para os setores que se voltam a atender uma dada demanda solicitada. Ressalta-se que havendo interesse, a ferramenta pode ser implementada em outros espaços tanto em nível 
estadual quanto federal. A critério de informação, as cidades de São Luiz Gonzaga, Giruá e Horizontina, na mesma região, também contam com o aplicativo.

\section{CONHECENDO UMA FERRAMENTA GEOTECNOLÓGICA}

Para fazer uso do aplicativo Cidadão Mobile, os habitantes de Santo Ângelo precisam dar conta de realizar uma série de procedimentos, sendo o primeiro deles nada mais nada menos que realizar o download desta ferramenta. Para isso, o cidadão deve acessar o site da prefeitura municipal de Santo Ângelo: http://www.santoangelo.rs.gov.br, indicado na Figura 02.

Figura 02: Página inicial do site da prefeitura municipal de Santo Ângelo, RS.

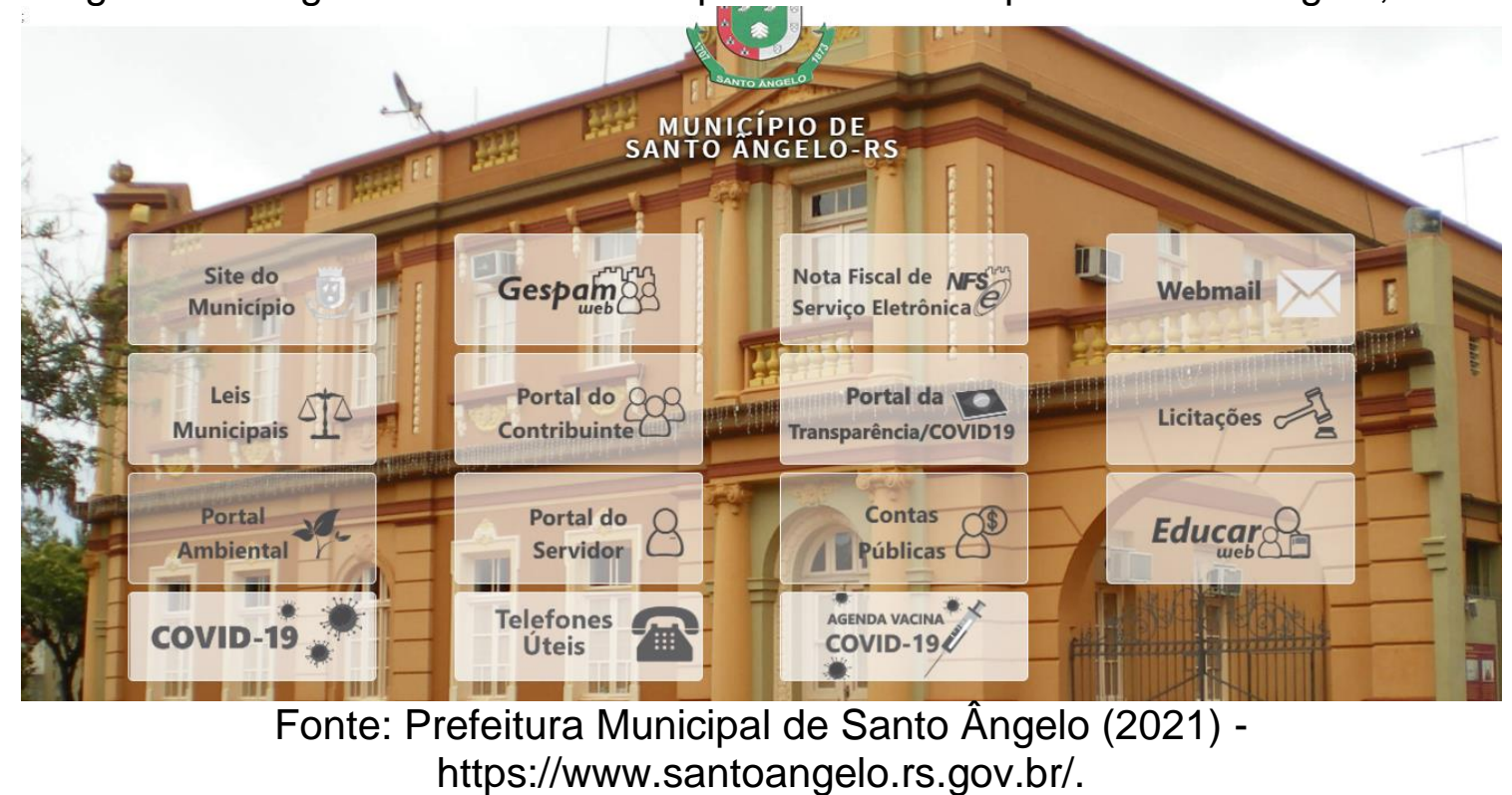

Após abrir a página inicial, deve-se clicar no ícone "site do município" e, posterior, na aba "Cidadão Mobile" para fazer o download. Na aba também constam informações sobre o uso e as funcionalidades do aplicativo. A Figura 03 ilustra o que deve ser feito nessa etapa. 
Figura 03: Página inicial do site do município de Santo Ângelo, indicando a opção Cidadão Mobile.

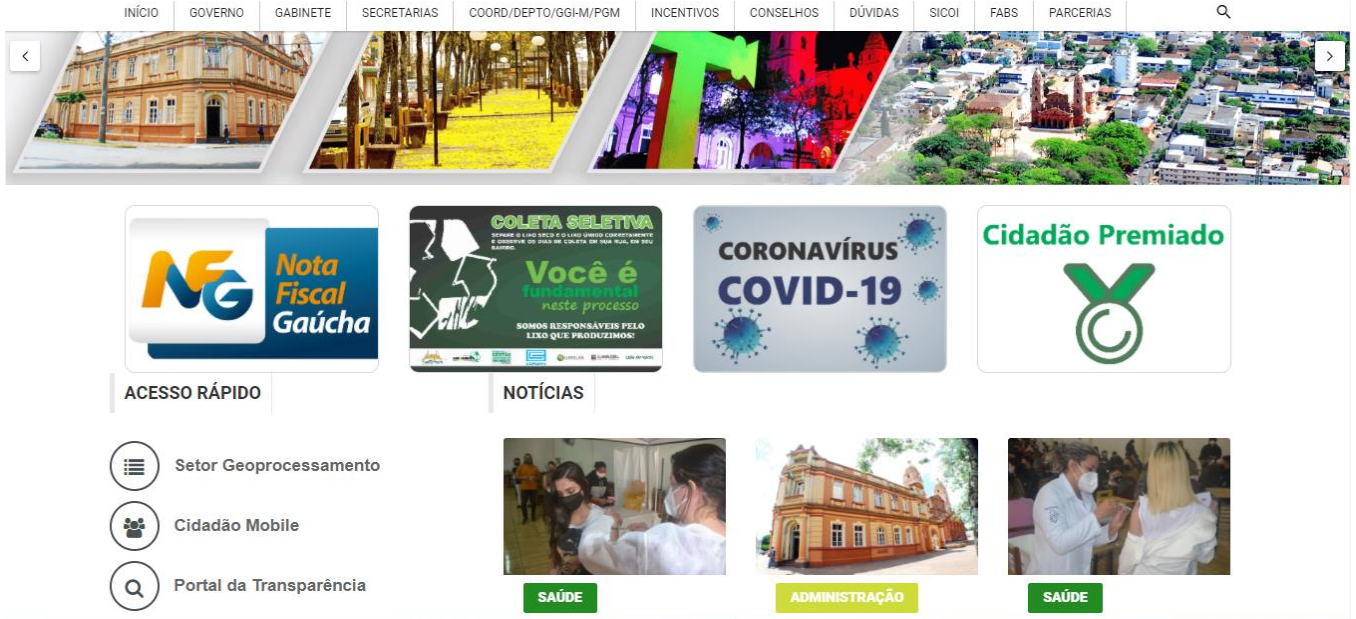

Fonte: Prefeitura Municipal de Santo Ângelo (2021) https://www.santoangelo.rs.gov.br/municipio.htm.

Vale destacar que o software pode ser baixado em dispositivos celulares com sistema operacional Android ou iOS. Com o Cidadão Mobile instalado, ao abri-lo pela primeira vez, será solicitado a criação de um cadastro. O usuário deverá, portanto, clicar na opção "registrar-se" e realizar o preenchimento dos campos demonstrados na Figura 04A. Quando estiver pronto, retorna-se à tela inicial onde o usuário deverá preencher os campos "CPF" e "senha" (Figura 04B).

Figura 04: (A) Interface "crie sua conta" do aplicativo Cidadão Mobile. (B) Página inicial do Cidadão Mobile.

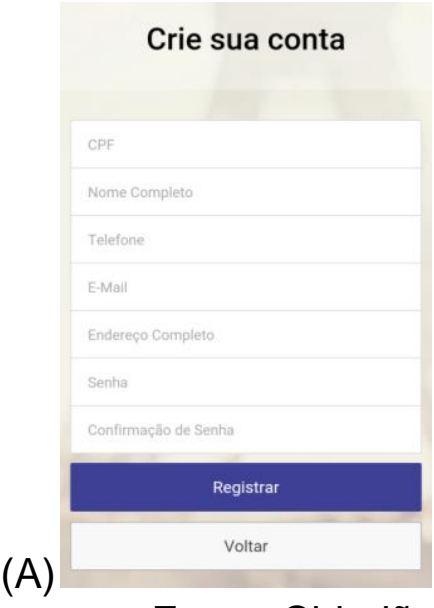

(B)

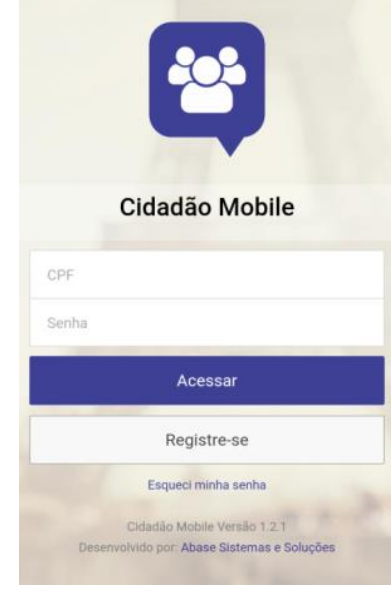

Fonte: Cidadão Mobile (2021) -

https://www.santoangelo.rs.gov.br/helpcidadaomobile/. 
Após informar seus dados de acesso, o cidadão deve escolher em qual município deseja utilizar o Cidadão Mobile. Nesse caso, o município de Santo Ângelo. Com o município escolhido, direciona-se para uma lista onde constam todas as opções para solicitações de serviços à prefeitura e, por sua vez, quando o tipo de serviço desejado é assinalado, guia-se para a tela de "preenchimento da solicitação". Nela, deverão ser alocados os dados do solicitante bem como poderão ser anexadas fotos relacionadas à solicitação.

As Figuras 05A, 05B e 05C sintetizam o passo a passo das etapas descritas no parágrafo acima.

Figura 05: (A) Interface das funções "selecione o município"; (B) "Selecione o serviço"; e (C) "preencha a solicitação", respectivamente, do Cidadão Mobile.

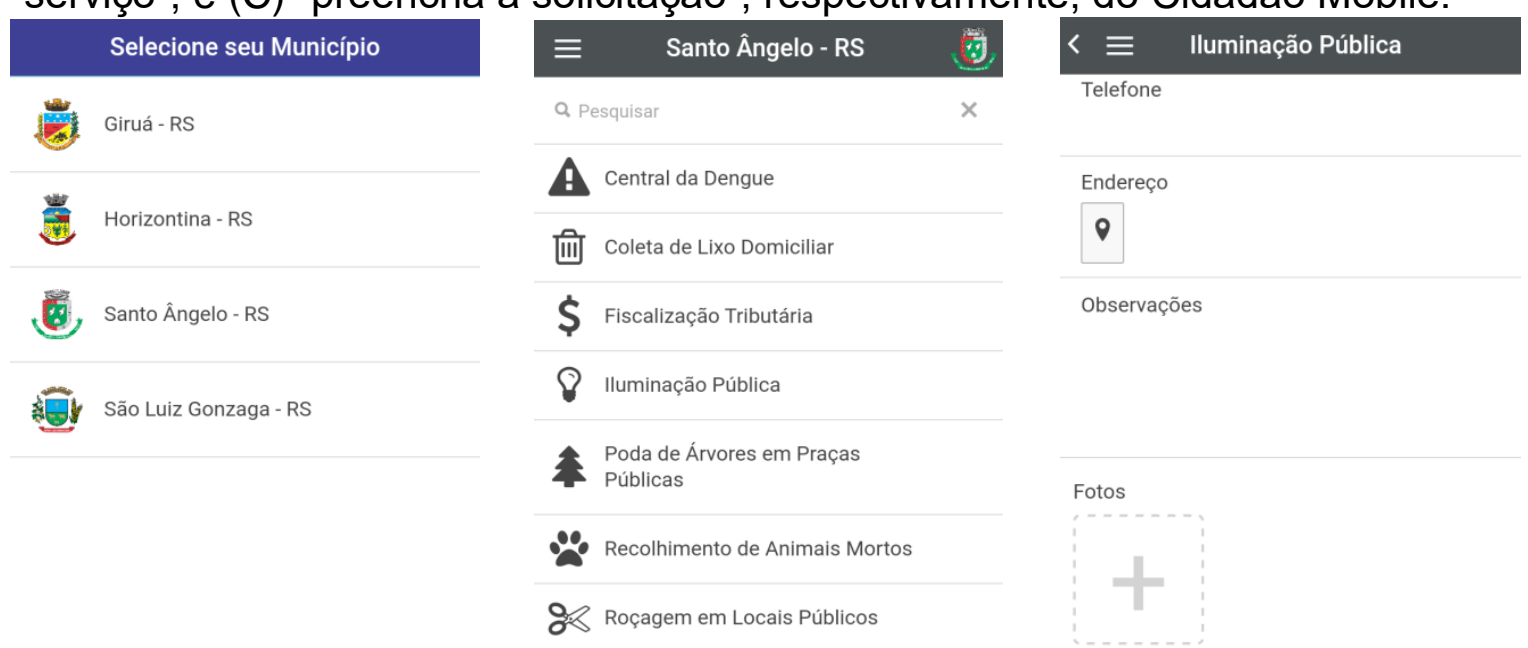

(A)

(B)

(C)

https://www.santoangelo.rs.gov.br/helpcidadaomobile/.

Ao finalizar o preenchimento da solicitação, basta clicar em "enviar" e aguardar que o poder público desempenhe suas funções, melhorando a qualidade dos serviços prestados à população. A respeito dos serviços que são possíveis solicitar pelo aplicativo Cidadão Mobile destacam-se a manutenção de logradouros públicos e os serviços de iluminação pública como as trocas de lâmpada, além de também permitir que o contribuinte faça denúncias sobre a fiscalização de obras, veículos estacionados em locais proibidos e a fiscalização tributária. 
Pode-se ainda contar com acesso a central de dengue, que monitora os casos da doença e possíveis focos do mosquito no município. Outrossim, em um cenário mais recente, instaurado pelo contexto sanitário de pandemia da COVID-19 que assola o mundo desde 2020, há o monitoramento de casos e locais com maior transmissão do coronavírus, a fim de controlar os efeitos da pandemia em Santo Ângelo.

Voltando ao momento em que o usuário envia a sua solicitação à prefeitura, esta logo recebe a notificação de uma ocorrência a qual é processada - melhor dizendo, georreferenciada - por um sistema de coordenadas geográficas, determinando o local exato de tal ocorrência. $E$ isso só é garantido por conta das geotecnologias que auxiliam, juntamente à atuação de profissionais da área da Geografia e da Computação, o poder local a fazer a análise do espaço para que sejam atendidas as demandas de sua população.

Uma destas geotecnologias é o Geoprocessamento que é definido como "[...] um conjunto de técnicas computacionais que opera sobre bases de dados (que são registros de ocorrências) georreferenciados, para transformá-los em informação relevante" (POLIDORO; BARROS, 2010, p. 86 apud CÂMARA, 2007, p. 11), tendo, portanto, importante papel no planejamento, ordenação, monitoramento e gestão do território.

Há de se citar, nesta perspectiva, a atuação dos SIG os quais também são essenciais no processo de planejamento, contribuindo na sistematização dos dados e/ou ocorrências e são definidos, de acordo com Polidoro e Barros (2010, p. 16), por serem "[...] valiosas ferramentas computacionais que tornam possível a análise e tratamento de informações geográficas e a posterior disponibilização dessas, como suporte à tomada de decisões".

Assim, observa-se que o Cidadão Mobile, a partir de métodos e técnicas de geocodificação espacial das solicitações para melhorias nos serviços públicos oferecidos no espaço de Santo Ângelo, "[...] possibilita a gestão do território, e é de grande valia na elaboração de políticas públicas, pois permite identificar no campo visual a resposta a perguntas como onde e por que ocorrem tais fenômenos e onde 
EDUCAÇÃO, SAÚDE

ETECNOLOGIA

26 A 28 DE OUTUBRO DE 2021

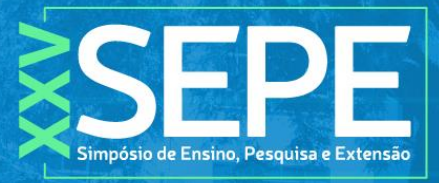

TRABALHO COMPIETO

atuar para saná-los ou ainda prioriza os locais que sofrerão interferências" (POLIDORO; BARROS, 2010, p. 87).

Correlacionando a importância desse aplicativo para com a gestão territorial e o desenvolvimento do município analisado com a prática educativa, percebe-se que tal ferramenta pode impactar de maneira bastante satisfatória no que tange à participação dos munícipes na geração de dados para gestão do território e, por conseguinte, na educação, sobretudo no ensino de Geografia que corresponde à área de interesse do primeiro autor.

Isso porque pensar o ensino de Geografia envolve termos consciência das características sociais de cada época. Santos (1994) aponta que "[...] o processo de aprendizagem deve, em primeiro lugar, partir da consciência da época em que vivemos" (SANTOS, 1994, p. 121). No contexto hodierno, como já dito, a "era digital" vem se tornando cada vez mais presente e, por isso, no ensino de Geografia, notase a necessidade de serem inseridas possibilidades de estudar o espaço geográfico a partir de engenharias desta época, assim, o aplicativo se mostra como uma interessante ferramenta para a gestão territorial, como também para práticas pedagógicas voltadas para a educação para a cidadania, ou seja, que conduzam os estudantes a pensarem o espaço em que estão inseridos e intervirem ativamente nele.

\section{CONCLUSÃO}

Levando em consideração o que foi analisado e discutido neste trabalho, infere-se que, ao aliar a aplicação de (geo)tecnologias no suporte ao atendimento de serviços públicos demandados pelos habitantes de Santo Ângelo, é possível gerar mapas que possibilitam uma fácil leitura dos dados espaciais, tanto para os planejadores municipais como para os munícipes.

Tal proposição vai de encontro com Mendes (2019, p. 47) que assinala que "[...] cada vez mais as geotecnologias vêm contribuindo de forma positiva para estudos de avaliação do espaço, de modo que a utilização de softwares e metodologias específicas pode favorecer para uma análise integrada do espaço de forma melhorada" (MENDES, 2019, p. 47), e é por isso que o Cidadão Mobile 
aplicado em Santo Ângelo proporciona o estabelecimento de políticas públicas de gestão do território que realmente lhes são efetivas.

Assim, as diversas ferramentas geotecnológicas se tornam fundamentais não só para a formação profissional do geógrafo (bacharel ou licenciado), mas também no processo de tomada de decisão, sobretudo no que tange o planejamento de planos diretores ou a resolução de problemas demandados no espaço municipal, uma vez que "[...] permite ser pontual no lançamento das informações, agregarem vasta quantidade de elementos podendo contribuir para uma gestão territorial eficiente" (POLIDORO; BARROS, 2010, p. 96).

Desse modo, por fim, será alcançada, de fato, uma tecnologia contemporânea que, quando realizada corretamente, promoverá o desenvolvimento municipal e consequentemente de sua população. As geotecnologias estão cada vez mais nesse meio para isso: dar fomento à adoção de políticas públicas sérias e compromissadas a atender da melhor forma as urgências dos habitantes. Em Santo Ângelo, com o Cidadão Mobile, a gestão terrirorial e a população só tendem a ganhar com isso. Do mesmo modo, a promoção de uma cultura cidadã tem impacto na construção de pessoas mais críticas e capazes de intervir conscientemente em suas realidades.

\section{AGRADECIMENTOS}

Agradecemos a bolsa o Programa de Licenciaturas (PROLICEN-UFSM) concedida ao $1^{\circ}$ autor.

\section{REFERÊNCIAS}

ABASE SISTEMAS E SOLUÇÕES LTDA. Em Santo Ângelo (RS), aplicativo permitirá maior integração entre população e prefeitura. Três de Maio/RS, 2021. Disponível em: <https://www.abase.com.br/noticias/gespam/em-santo-angelo(rs),aplicativo-permitira-maior-integracao-entre-populacao-e-a-prefeitura>. Acesso em: 17 de ago. 2021.

CIDADÃO MOBILE. Prefeitura Municipal de Santo Ângelo. Manual de utilização, 2021. Disponível em: <https://www.santoangelo.rs.gov.br/helpcidadaomobile/Index.html>. Acesso em: 17 de ago. 2021. 
POLIDORO, M.; BARROS, M. V. F. Utilização de geotecnologias no suporte a gestão de políticas públicas municipais. Revista Eletrônica da Associação dos Geógrafos Brasileiros - Seção Três Lagoas, n. 11, p. 81-98, 2010. Disponível em: $<$ https://desafioonline.ufms.br/index.php/RevAGB/article/view/656>. Acesso em: 17 de ago. 2021.

LAUDARES, S. Geotecnologias ao alcance de todos. Curitiba: Appris, 2014.

MENDES, I. A. da S. O uso de geotecnologias na organização do espaço. Cadernos do Leste. Universidade Federal de Minas Gerais, vol. 19, n. 19, p. 35-50, 2019. Disponível em: <https://periodicos.ufmg.br/index.php/caderleste/article/view/13157/10398>. Acesso em: 17 de ago. 2021.

SANTO ÂNGELO. Prefeitura Municipal de Santo Ângelo. Site do município, 2021. Disponível em: <https://www.santoangelo.rs.gov.br/>. Acesso em: 17 de ago. 2021.

SANTOS, M. Técnica, espaço, tempo: globalização e o meio técnico-científico informacional. São Paulo: HUCITEC, 1994. 